\title{
Fundamentals of Language and Language Learning: A Collaborative Initiative for the Implementation of a Common Online Language Training Component in the First-Year Language Curriculum ${ }^{1}$
}

\author{
Alena Barysevich \\ University of Guelph \\ Canada \\ Liz Smeets \\ York University \\ Canada \\ School of Languages and Literatures \\ University of Guelph \\ Canada
}

\section{Background}

The School of Languages and Literatures (SOLAL) at the University of Guelph (Canada) offers a large variety of language courses, including German, French, Italian, Portuguese, and Spanish, with an enrollment of more than a thousand new first-year students each year. Although with different languages and cultural backgrounds and specializations, all first-year students come to SOLAL to start a unique journey of learning languages and their cultures at the university level. One of SOLAL's mandates is to form proficient and autonomous communicators with a broad education while providing them with opportunities to develop strong language awareness to participate in the global community.

In response to calls for more global, inclusive, and effective approaches to language learning at $S O L A L$, this paper presents an overview of a large-scale initiative to redesign the second/foreign language learning model for first-year students coming to our School. The Fundamentals of Language and Language Learning is a School of Languages and Literatures-wide introductory, mandatorily completed mini-course offered annually to an incoming cohort of first-year students. The four modules of this language training component (10-15 hours of autonomous work) are integrated, as a complementary component, into the first-year language curriculum of the programs in French Studies, Spanish and Hispanic Studies, Italian Studies, and German Studies. The modules are developed by a team of professors in (applied) linguistics, second language acquisition and language pedagogy after thorough consultation with faculty members teaching introductory language courses and (under)graduate students from the School of Languages and Literatures at the University of Guelph².

\section{Purpose and objectives}

The context in which we teach languages today at SOLAL has drastically changed due to (among other factors) accelerated migration, changes in students' sociolinguistic profiles, extremely rapid development of technology, and the necessity for hybrid or fully online education due to the COVID-19 pandemic. As we reflect on our Canadian society, we realize that students at SOLAL are part of increasingly multilingual, multicultural, digitally competent, experience-driven community, and very open to embrace different languages and cultures. At the School of Languages and Literatures, we believe that learning languages should go beyond just learning a language. It is also about general education and awareness about languages; it is also about intercomprehension across languages and cultures.

The general purpose of the Fundamentals of Language and Language Learning is: 
Barysevich, Alena, Liz Smeets and School of Languages and Literatures. « Fundamentals of Language and Language Learning: A Collaborative Initiative for the Implementation of a Common Online Language Training

Component in the First-Year Language Curriculum. » Nouvelle Revue Synergies Canada, №14 (2021)

- $\quad$ To enhance evidence-based learning practices widely informed by students and language instructors' needs;

- $\quad$ To provide a more general education and a more linguistically supportive, strategic, and user-friendly language learning experience to all students coming to learn languages;

- $\quad$ To maximize the learning potential of second/foreign language learners.

The Fundamentals of Language and Language Learning address a couple of issues. First, this mini course responds to recurrent concerns expressed by language instructors ${ }^{3}$ about the intimidating lack of fundamental knowledge among students about how languages are generally structured, how they function and interconnect with each other. According to instructors across language programs, most first-year language students typically show insufficient awareness and familiarity with:

- Basic grammar categories and concepts (adjectives, (ad)verbs, (pro)nouns, prepositions, (in)direct objects, subject, predicate, complement, clause, phrase, etc.);

- $\quad$ Critical linguistic concepts (morpheme, lexeme, affix, root, stem/base, gender, case, etc.);

- Fundamental components or subdisciplines of language (phonetics, phonology, morphology, syntax, semantic and pragmatics).

In French, for example, students struggle to comprehend the relationship between word pairs of the same lexeme as "bien" and "bon" (meaning both "good" in English) or "mieux" and "meilleur" (meaning both "better" in English), as in (1a-b). This leads to the very common misuse of these terms.

1a. ENGL:: You work better today.

FREN. : Tu travailles mieux ( ${ }^{*}$ meilleur) today ${ }^{4}$.

1b. ENGL.: Your work is better today!

FREN. : Ton travail est meilleur ('mieux) aujourd'hui.

This challenge to navigate across the words of the same lexeme could be overcome if students had a better understanding of the difference in nature and use between two grammatical categories - adjectives and adverbs.

In Romance languages, such as Spanish, Italian, and French, for example, the ability to understand the difference between a direct and an indirect object is crucial for comprehending which pronoun to use, as these languages have different pronouns for direct and indirect objects where English uses a single form, as illustrated in Table $2 a$ and $2 b$ :

Table 2a

Direct and indirect objects across Romance languages

\begin{tabular}{lcc}
\hline & INDIRECT PRONOUNS & DIRECT PRONOUNS \\
\hline ENGLISH & Silvia explains (to) him how the game works. & Silvia adores him. \\
ITALIAN & Silvia gli spiega come funziona il gioco. & Silvia l'adora. \\
SPANISH & Silvia le explica (a) cómo funciona el juego. & Silvia lo adora. \\
FRENCH & Silvia lui explique comment le jeu fonctionne. & Silvia l'adore. \\
\hline
\end{tabular}


Barysevich, Alena, Liz Smeets and School of Languages and Literatures. « Fundamentals of Language and Language Learning: A Collaborative Initiative for the Implementation of a Common Online Language Training Component in the First-Year Language Curriculum. » Nouvelle Revue Synergies Canada, №14 (2021)

Table 2b

Direct and indirect object pronouns across Romance languages

\begin{tabular}{lcc}
\hline & INDIRECT PRONOUNS & DIRECT PRONOUNS \\
\hline ENGLISH & him & him \\
ITALIAN & gli & l' \\
SPANISH & le & lo \\
FRENCH & lui & l' \\
\hline
\end{tabular}

Additionally, the ability to differentiate between a direct and indirect object is crucial for understanding the order of direct and indirect pronoun clitics, as illustrated in the examples taken from English and Italian in (2c).

2c. ENG. Silvia explains it to him .

ITAL. Silvia glielo spiega. ( ${ }^{\star}$ Silvia logli spiega) order $=$ direct object $($ it $)-->$ indirect object $($ him $)$ order $=$ indirect object $(g / i)$--> direct object $(l o)$

And in German, for example, being able to identify various clause types, such as main and subordinate, is crucial for understanding the placement of verbs in the sentence. In German main clauses, the verb is the second element in the sentence, in subordinate clauses, the verb typically comes at the end as it is illustrated in (3a-b):

(3a) GERM. Ich lerne Deutsch. Es macht Spaß.

'I learn German. It is fun.'

Ich lerne Deutsch. *Es Spaß macht.

(3b) GERM. Ich lerne Deutsch, weil es Spaß macht.

I learn German, because it fun makes.

'I learn German, because it is fun.'

*Ich lerne Deutsch, weil es macht Spaß. ungrammatical structure

Learners of German often struggle with analyzing a complex sentence by its separate clauses and finding the subject, verb, and object of each individual clause. Furthermore, the ability to differentiate subjects, direct and indirect objects is a prerequisite for grasping the concept of grammatical case (nominative case/subject vs. accusative case/ direct object vs. dative/indirect object), an aspect central to the German language as it surfaces on determiners, nouns, and adjectives.

There are numerous other examples from the language classrooms that could be mentioned here. This compromised linguistic knowledge of pre-basic concepts, partially due to insufficient pre-university language training, hinders language learning at the university level. In consequence, language instructors at all levels spend a large amount of time and energy re-explaining introductory concepts, which takes away time from communicative practice and higher order thinking activities with the target language. The Fundamentals of Language and Language Learning mini course provides an explicit (yet engaging) instruction and scaffolded training of basic, fundamental properties and concepts of the language through the lens of linguistics and its application to the target language with the goal to maximize and accelerate second/foreign language acquisition. The course therefore provides a complementary method and a variety of tools for more effective and more critical language learning.

Secondly, the Fundamentals of Language and Language Learning represents a specialized pedagogical approach in setting a solid foundation for a richer and more complete modern language learning experience. 
Barysevich, Alena, Liz Smeets and School of Languages and Literatures. « Fundamentals of Language and Language Learning: A Collaborative Initiative for the Implementation of a Common Online Language Training Component in the First-Year Language Curriculum. » Nouvelle Revue Synergies Canada, №14 (2021)

This mini course responds to the question "What is the modern lifelong language learner?'. The pedagogy behind this mini course recasts modern language learning as a site of linguistic and cultural awareness and diversity. It shifts towards more strategic, easier, and more intercomprehensive language learning across linguistic and cultural boundaries (Donato \& Oliva, 2016; Oliva, Donato \& Ricciardelli, 2019). The Fundamentals of Language and Language Learning provides a transformative approach to modern language pedagogy that is better aligned with students' sociolinguistic profiles and the context of teaching and learning languages (multilingual and multicultural society; Galante, 2021; Piccardo, 2018; Piccardo \& Galante, 2017; Piccardo \& Puozzo, 2015) and better responds to the new interdisciplinary paradigm in language learning of the twenty-first century.

Finally, the Fundamentals of Language and Language Learning seeks more personalized scaffolding, while building a stronger linguistic foundation, and aims at decreasing the current drop-off rate in language courses (mostly among 'non-humanities' students), as well as improve students' curiosity, motivation, and confidence. Furthermore, while language departments typically offer an introductory course in linguistics to language students, such a course is not directly related to applied language learning and does not focus on how linguistic foundations could help students to learn a new language. The Fundamentals of Language and Language Learning mini course equips students with effective tools and uses reasoning from linguistics in a way that is accessible and useful for language learning. This language training in the form of a minicourse could be particularly beneficial in schools, departments, and units with a short supply of linguists in targeted (second/foreign) languages ${ }^{5}$.

\section{Guiding principles}

The pedagogy behind the Fundamentals of Language and Language Learning targets global and integrative approaches towards language learning, interdisciplinarity by design and critical thinking.

Global approach and interdisciplinary by design - We built the Fundamentals of Language and Language Learning mini course at the intersection of linguistics, second language acquisition (SLA), language pedagogy and Mind, Brain and Education field (MBE). We believe that research-informed, comprehensive descriptions provided by multiple disciplines focusing on language are important to be translated in language teaching and learning in educational settings (Block, 2003; Germain, 2010; Ellis, 2012; Kramsh, 2009; Tokuhama-Espinosa, 2010; VanPatten, 2017; VanPatten \& Benati, 2010). We therefore developed four modules on the premises of basic understanding from linguistics and empirical evidence from SLA as an integral part of teaching and learning the target language. This global approach connects disciplines and provides more cognitive and effective second/foreign language learning.

The Fundamentals of Language and Language Learning is built around engaging self-assessed activities that encourage students to critically think like linguists (to observe, to compare, to analyze and to notice properties of the language) and like diplomats (to learn languages and cultures through the method of intercomprehension). In other words, our modules constitute an exercise in comparison, observance, pattern recognition, interpretation, and application, which are deeply based in navigation across languages and their history and culture.

Integrative approach and method of intercomprehension - The Fundamentals of Language and Language Learning is based on the method of intercomprehension and a comparative view of languages with a main reference to English ${ }^{6}$ as the first language. Through a combination of short engaging videos, written illustrations, polls, glosses and a variety of interactive activities, students learn to use a range of basic yet fundamental linguistic concepts at the level of sentence structure (syntax), word formation (morphology), pronunciation (phonology and phonetics) and language variation and change (sociolinguistics). Students are engaged in building natural bridges between languages and in analyzing their similarities and differences. The students' attention is drawn to the fact that they dive into the language learning experience with a tremendous pre-existing knowledge from their L1 (and other learned languages) and cultural baggage attached (Cummins, 1981; Donato \& Oliva, 2014, 2016; García, 2011; Oliva, Donato \& Ricciardelli, 2019). The modules' content 
Barysevich, Alena, Liz Smeets and School of Languages and Literatures. « Fundamentals of Language and Language Learning: A Collaborative Initiative for the Implementation of a Common Online Language Training Component in the First-Year Language Curriculum. » Nouvelle Revue Synergies Canada, №14 (2021)

focuses on activating prior knowledge from their mother tongue (English) and personal experiences in other acquired languages in combination with properties of the target language and facilitates memory retention by engaging learners in interleaved and spaced practices (Tokuhama-Espinosa, 2010). By connecting the target language to earlier acquired languages, students also activate and gain transversal skills to link different concepts and navigate across language and cultural realities (Escudé \& Janin, 2010; Marshall \& Moore, 2013; Moore, 2006; Moore et al. 2020). Our approach is integrative as we target interconnectedness and intercomprehension between language and culture.

In addition to discovering language commonalities and learning strategies, particular attention is paid to explicit instruction about specific difficulties in the second/foreign language under study in comparison to L1 English (Donato \& Oliva, 2014; Ellis, 2009, 2012). For example, in the chapter What is language? How do languages work? language learners become aware of the possibility of negative transfer of one language onto another and how it affects their learning of the target language at the level of pronunciation, syntax and vocabulary. In the chapter Word formation and sentence structure, students learn to identify the subject, verb, and object as well as other elements such as adverbs and adjectives considering cross-linguistic similarities and differences. For example, students notice that the order of adjectives and nouns in English (i.e., adjective-noun) is important in comparison to French, Italian, Portuguese and Spanish (i.e., mostly noun-adjective but also adjective-noun). Students taking German language courses are introduced via comparison between English and German to the High Consonant Shift and to the rules of the position of the verb as central elements to understand how German is structured and how it functions. The chapter Sounds of Language focuses, among other things, on the sounds that are problematic in the target language of study and explicit instruction of their correct pronunciation (e.g., the grapheme "ch" as in "chocolate" is pronounced as /t $\mathrm{f} / \mathrm{in}$ English, but as /J/ in French (chocolat), as / $\mathrm{k} /$ in Italian (chiesa - church) and as /ç/ or / $\mathrm{x} /$ in German (sprechen (to speak) vs. Sprache (language)).

\section{Learning model}

The structure of each of the four online modules follows a backward design approach, setting first the learning objectives that relate to the general goal followed by aligning the assessments (pre- and post-assessment and summary) with pedagogical activities (participatory learning, instruction) to the predetermined learning outcomes (Wiggins \& McTighe, 2011).

Each module follows the BOPPPS learning model for lesson planning to facilitate a smooth progression through the content. BOPPPS is an acronym for: Bridge-in, Outcomes, Pre-assessment, Participatory Learning, Postassessment, and Summary, as illustrated in Figure 1 (Appendix 1). Each module starts with a bridge-in section that introduces a series of misconceptions/myths and facts related to the topic of that module. The preassessment section of each module measures students' prior knowledge of the topic through a series of short exercises and open-ended questions. The participatory learning section of each of the four modules presents the core content and provides students with explicit fundamental explanations, explanatory videos, and practical tools to complete interactive self-assessed activities. The post-assessment section of each module brings together the newly acquired concepts through the completion of a series of tasks. The summary component wraps up the learning experience and allows students to critically reflect on what they have learned in each module and how it could /should be applied in their own second/foreign language learning.

The core part of each of the four modules explains concepts using examples from the English language, followed by inclusive and similar academic content in the target language (French, Italian, Spanish, or German), as illustrated in Figure 2 and 3 (Appendix 1). Using this structure, students master the interdependency of competences or transfers between languages (Cummins, 1981); they learn to make comparative analyses, to move between languages and to focus more on what is potentially hard in the second/foreign language of study by focusing on how it differs from their native tongue (or previously acquired languages). 
Barysevich, Alena, Liz Smeets and School of Languages and Literatures. « Fundamentals of Language and Language Learning: A Collaborative Initiative for the Implementation of a Common Online Language Training Component in the First-Year Language Curriculum. » Nouvelle Revue Synergies Canada, №14 (2021)

Each of the four modules can be completed in two-to-three hours of study, although students may find that they spend more or less time on topics depending on their interests and experience. As each module is divided into five discrete steps (bridge-in, pre-assessment, participatory learning, post-assessment, summary), students can choose to study all materials at once or work through them in 2-3 steps during 30-minute breaks or spread the exercises over any period which suits them. Each chapter also integrates the glossary of the main linguistic and grammar concepts and the language library with optional additional readings and sources.

\section{Content and learning objectives}

The language training (the mini course) consists of four modules:

- What is language? How do languages work?

- Word formation and sentence structure.

- Sounds of languages.

- $\quad$ Languages in context: time and space.

In the module What is language? How do languages work? students are introduced to the various units of language: phonetics and phonology, morphology, syntax, semantics, and pragmatics. They become familiar with the idea that words and sentences consist of smaller building blocks that are combined in systematic ways across languages. They also learn how learning a second language is different from learning a first language and understand how the native language typically forms the starting point for learning a foreign language. Students learn about the main principles or components present in all languages. Through a combination of short engaging videos (with integrated quizzes) and written illustrations (charts, timelines, glosses) and a variety of interactive activities (polls, discussions, etc.), students learn to use a range of fundamental linguistic concepts at the level of sounds (pronunciation), of words (word formation) and sentences (sentence structure). This module also provides strategies and resources on how to connect with the learning community of the target language and how to learn language effectively.

In the module Word formation and sentence structure students learn how words can be built and understood by combining and teasing apart morphemes, helping students to increase their vocabularies. They furthermore learn to identify the function of words in a sentence (e.g., subject, verb, direct/indirect object) and acquire the technical vocabulary used in the classroom related to grammatical categories (e.g. (pro)nouns, determiners, (ad)verbs), adjectives).

In the module Sounds of language, students learn to read words in IPA and use it as a tool to look up the pronunciation of and practice with foreign words. Students learn to assess the nature of foreign accents and understand why people have them. They learn that it is often hard to perceive sound contrasts in a foreign language that do not exist in their native language and then learn how they can manipulate their tongue, lips, and mouth to produce these problematic sounds. A strong emphasis is placed on identifying the sounds of the foreign language that do not exist in English and practice to articulate these sounds (corrective phonetics).

The module Languages in context: time and space is developed from the perspective of integrative pedagogy and helps students identify with their target language and its cultural properties. Going through some basic examples of historical changes in pronunciation, word meaning and sentence structure, students realize that languages are always in contact, they are changing systems, and understand how languages are historically related to other languages, helping them navigate across languages (e.g., how the Romance languages relate to Latin and how English and German are related). This module also focuses on regional and social similarities and differences in word choice and pronunciation, adding to students' understanding that a language is not a single fixed system and that no two speakers speak the same way.

The Foundational Language Learning mini-course is introduced at the School of Languages and Literatures at the beginning of first-year courses (French, German, Italian, Spanish). Each program and course instructor can 
Barysevich, Alena, Liz Smeets and School of Languages and Literatures. « Fundamentals of Language and Language Learning: A Collaborative Initiative for the Implementation of a Common Online Language Training Component in the First-Year Language Curriculum. » Nouvelle Revue Synergies Canada, №14 (2021)

choose their own pace. In general, students would take the first two modules (parallel to their core language curriculum) within the first month of the course. This ensures that all students have the fundamental linguistic knowledge needed so that instructors can focus on the target language without having to explain basic concepts. The modules on phonetics and phonology Sounds of the languages ${ }^{7}$ as well as the module Languages in context: time and space could be merged at any point of the first-year course. The asynchronous nature makes the modules and their parts accessible to any language program and at any time during the language acquisition process. The flexibility of the modules' components furthermore allows instructors to pick and choose the modules (or parts of it) relevant for their students and according to their learning objectives and students' needs. For example, it is possible to implement only the chapter Sounds of language if one aims to focus on corrective phonetics. It is also possible to implement the chapter Language in context after students have acquired some basic vocabulary in the target language. The learning platform used to create the modules provides learning analytics and performance details from each individual student, which allows instructors to tailor language classes to each group.

\section{Need and benefits from linguistics in language teaching and learning}

Although applied linguistics focuses on language, it is still often disconnected from day-to-day practices in the language classroom (Block 2003; Germain, 2010; Ellis \& Shintani, 2014; Swain, 2018). Most foreign language instruction has moved away from focusing on the form of the language (grammar teaching) and error correction because knowing about the language does not make a student able to speak the language.

We highly support the idea that communicative practices and immersion in the language are crucial for becoming a proficient speaker of the language. However, we also believe that basic linguistic training could be very useful to modern language learners and instructors. It has been shown indeed that the lack of basic linguistic knowledge in students and language instructors could jeopardize the effectiveness of the learning process (DeKeyser 2003; DeKeyser \& Goretti 2015; VanPatten \& Benati, 2010). We believe that understanding the fundamental structures underlying languages is a powerful tool for language learning. We believe that basic awareness about languages and their commonalities and differences is also extremely beneficial to language learners, especially to those learning a target language mostly in a classroom setting in a minority environment (such as Italian, Spanish in Canada or French in highly majority anglophone provinces). We also adhere to N.C. Ellis (2005) and R. Ellis $(2009,2012)$, and therefore believe that foreign language learners could benefit substantially from explicit knowledge construction when it comes to some linguistic aspects (syntactic functions, word grammatical categories and their features, negative evidence, understanding cross-linguistic commonalities and differences).

A crucial issue within theoretical Second Language Acquisition research is the question as to what learners can acquire simply based on the input they receive (through practice with the language in naturalized settings) and for which phenomena of the language it can be beneficial to receive explicit correction or information about why a certain construction is ungrammatical (negative evidence). Foreign language learners often make incorrect generalizations based on properties of their mother tongue. Negative evidence is therefore argued to be particularly helpful for grammatical phenomena where the $L 1$ and $L 2$ differ. This means that the learner receives explicit correction of the error.

McManus and Marsden (2017, 2019a, 2019b), for example, looked at whether classroom learners could benefit from explicit instruction for learning aspectual distinctions in French, which, crucially, differ from how they are expressed in English (focus is on past habituality, past ongoingness and past perfectivity). The results from both comprehension and production tests showed that learners who received information about the formto-meaning mappings both in the L1 and in the L2 performed better than learners who received explicit instruction on aspectual distinctions only in the $\mathrm{L} 2$ or those who received no explicit instruction at all.

Basic knowledge of linguistics (in particular, knowledge of word formation and sentence structure of languages in general and of the target language) is crucial for foreign language learners to understand classroom 
Barysevich, Alena, Liz Smeets and School of Languages and Literatures. « Fundamentals of Language and Language Learning: A Collaborative Initiative for the Implementation of a Common Online Language Training Component in the First-Year Language Curriculum. » Nouvelle Revue Synergies Canada, №14 (2021)

instruction. It is also crucial for the learner that the language instructor has a basic training in linguistics (i.e., some knowledge of morphology, and sentence structure of the target language) and can make connections with the student's (native) language(s), making it easier to respond to and to identify the needs of the students (Cunningham, 2015).

If the student and the language instructor have basic knowledge of the phonetics and phonology of the target language, for instance, and knowledge of the sounds that differ between the language of study and the native language, they can better understand why certain errors in pronunciation occur. For example, the French words $v u$ (past participle of the verb to see) and vous (in English, you, 2-person, singular and plural form) may be hard to distinguish for a native English speaker, and therefore hard to pronounce correctly, because the vowel (/y/), as in $v u, t u, n u$, is not used in English. Knowing how the L1 and the L2 differ and how to manipulate the articulatory system (e.g., knowing that the /y/ is articulated in the front of the mouth and /u/ at the back of the mouth) is helpful in knowing what to focus on. Or, for example, if a student has difficulties pronouncing the difference between /f/ (as in the French word font 'they do') and / $/$ / (as in the word vont 'they go'), it may be useful for the student if the instructor guides them to focus on the vibration of the vocal cords. It is therefore important for students and instructors to know how various sounds and sound contrasts are made in the mouth.

As with French, German uses various vowel contrasts that are not present in English and has various palatal and velar sounds (like /ç/ and /x/) that are not easily distinguished by native English speakers. While most sounds in Italian and Spanish are also used in English, there are some sounds that speakers may experience difficulties with (such as the palatal sound $/ \mathcal{K}$ in Italian words with "gli" as in "figlio") or where the letter-sound mapping is not the same in the L1 and L2 (e.g., English learners of Spanish tend to pronounce the pronoun "me" as [mi] instead of [me]).

With respect to syntax, explicit instruction of how the native language and the target language differ in the word orders they allow, can be useful for second language learners. White (1991), for example, studied the order of verbs and adverbs by French learners of English. French and English both allow an adverb (like often) to be placed in between an auxiliary and a lexical verb, as shown in (4):

4. Jean a souvent visité le musée. 'John has often visited the museum'

However, an adverb in English is not allowed to interrupt a verb and its direct object, in contrast to French, as is shown in (5a) and (5b):

(5a) FREN. : Marie regarde souvent la télévision. ENGL: *Marie watches often television.

Note. Adapted from White (1991), examples (6) and (7).
(5b)*Marie souvent regarde la télévision. Marie often watches television.

White (1991) found that students who were explicitly taught that (5a) is not allowed in English performed better on English verb-adverb placement than students who received positive evidence alone. Explicit instruction that in French an adverb cannot be placed between the subject and the verb can therefore speed up language acquisition.

Finally, basic knowledge of historical linguistics (e.g., history of English/French/Italian/Spanish/German) and sociolinguistics (e.g., how it is spoken differently in different regions or by different social classes) helps students be more connected to the culture associated with the language they are learning (integrative approach). Exploring word origins and derivation expands students' vocabulary and increases students' ability to build strategies which allow them to figure out the meaning of new words and rules. In turn, this helps to assimilate new words across languages, and gives students insights into the shared roots between the native language and the target language. Understanding how linguistic differences between speakers reflect social differences, helps students to connect to the language and use it more authentically outside the classroom. 
Barysevich, Alena, Liz Smeets and School of Languages and Literatures. « Fundamentals of Language and Language Learning: A Collaborative Initiative for the Implementation of a Common Online Language Training

Component in the First-Year Language Curriculum. » Nouvelle Revue Synergies Canada, №14 (2021)

\section{Feedback and final observations}

The first run of Fundamentals of Language and Language Learning in Winter $2021^{8}$ showed very promising results (see some of students' feedback in Table 1, Appendix 2). In general, students believed that the language/linguistic training was useful, informative, easy to assimilate, well structured and very engaging. First, students appreciated the cross-subject (interdisciplinarity) and cross-language perspective and expressed enthusiasm for this strategic way of learning languages. They appreciated that the mini course provides systematic language support embedded within the first-year course on how to learn a language. They furthermore valued the digital content, the alignment of the online mini course with the core content in the language classroom and the focus on less traditional (functional, digital, critical) literacies. They particularly loved the idea of being equipped with tools and resources to understand the building blocks of language instead of pure explanation and memorization of grammar rules. Students appreciated making connections with the language(s) they speak and realizing that each language is organized in a systematic way. We do understand, however, that the feedback we received so far is only based on a perception survey, and that more learning analytics should be explored, and empirical research should be conducted to evaluate the effectiveness of language/linguistic training on students' learning. This is the direction we hope to pursue in Fall 2021 and Winter 2022.

We also asked university language instructors who participated in this pilot-project to share with us some thoughts on their perception of the Fundamentals of Language and Language Learning training. As shown in Table 2 in Appendix 2, language instructors did appreciate the rich content of the Fundamentals of Language and Language Learning and praised it for its easily digestible, practical, non-technical and flexible presentation, which is useful for both first-year students and language instructors who are not specialists in linguistics. They valued the flexibility of the modules for its use within their language courses and the target on learning to learn. Language instructors also appreciated the online format of the course, as a contribution to the development of digital literacy (Belshaw, 2012) and language learning autonomy (Godwin-Jones, 2011) among first-year students. Some of the instructors were delighted to take direction towards the method of intercomprehension in second/foreign language pedagogy (see Table 2, Appendix 2).

To conclude, the mini course Fundamentals of Language and Language Learning is the result of lengthy reflections, questioning of current teaching pedagogy and long-time inspirations. In what follows, we present some general observations we will take away from this project.

At first, it appears to us that the current-day language learning model should be renewed and be oriented towards a more global and general education, be more inclusive, more interdisciplinary, more effective, and user-friendly. Language instructors and linguists who participated in this project developed the content using scientific research (from General Linguistics and Second Language Acquisition) and experience-based input from actual language classrooms. With this, our team developed a more conscious and more linguistically oriented training that targets students' needs and sociolinguistic profiles as well as core competencies. The SOLAL team argues that the modern language learner (i) should have a general understanding of and metalinguistic awareness about language, (ii) should be able to activate their inner capacity to navigate across languages, to notice universal patterns and to identify differences and similarities, (iii) should be well equipped for autonomous and sustainable language learning.

Secondly, although the project was initiated during the first months of the COVID pandemic (Winter 2020), the virtual collaboration between researchers, students, and staff from different programs within the School of Languages and Literatures was remarkable. We are very proud to create a cross-program and cross-subject online mini course which will make our students learn languages more easily, more effectively, more inclusively, and more critically. 
Barysevich, Alena, Liz Smeets and School of Languages and Literatures. « Fundamentals of Language and Language Learning: A Collaborative Initiative for the Implementation of a Common Online Language Training Component in the First-Year Language Curriculum. » Nouvelle Revue Synergies Canada, №14 (2021)

Thirdly, it is well known that not all language instructors have a background in or are familiar with concepts of linguistics and research in the field of SLA. The Fundamentals in Language and Language Learning therefore also provides professional development in the form of basic linguistic training of the target language for SOLAL's language instructors (full- and part-time faculty members, sessional lecturers, graduate teaching assistants and interns) to support their teaching (and their own learning) in the French, German, Italian, Spanish, Portuguese, and English classroom.

Finally, the online component blends effectively with the core-language content and complements implicit language learning with an explicit online component to accelerate second/foreign language acquisition. The explicit knowledge construction of some aspects of the target languages within the Fundamentals of Language and Language Learning module is also seen as an asset for the specific context of SOLAL's students at the University of Guelph - a pronounced French, German, Spanish, Italian and Portuguese minority setting. In sum, this modular online mini course hopes to somehow compensate for the lack of full-language immersion by equipping the students with some effective tools for modern language learning.

\section{Notes}

1 This project was generously funded by the Learning Enhancement Fund at the University of Guelph. Principal Investigator: A. Barysevich. Collaborators: L. Smeets (principal collaborator), D. Cornelio, R. Gomez, W. Lindinger, D. Mohan, and S. Parmegiani.

2 This project would not be possible without the valuable contribution of many full- and part-time faculty members, (under) graduate students and staff at the School of Languages and Literatures. We are very thankful to Angelina Candotti, Enrica Aurora Cominetti, Dawn Cornelio, Rosario Gomez, Kayla Hall, Margot Irvine, Wes Lindinger, Dillon March, Pilar Rodriguez Mata, Paola Mayer, Denise Mohan, Ruediger Mueller and Sandra Parmegiani.

${ }^{3}$ The project was initiated thanks to an idea expressed by Prof. Sandra Parmegiani (European Studies, Head of Italian Studies and Acting Director of SOLAL in 2019). Dr. Parmegiani shared her concerns about insufficient awareness among first-year students taking Italian courses of basic grammar concepts and raised the possibility of addressing this issue in all first-year language courses across different programs of the School of Languages and Literatures. Her constant support and valuable advice to the outcome of this initiative therefore should not be underestimated.

4 The asterix $\left(^{*}\right)$ is marking a form or a structure as ungrammatical.

5 The School of Languages and Literatures does offer some introductory linguistics courses. However, these courses are electives for students taking second/foreign languages courses and their objectives do not include the application of linguistic knowledge to learning the target language (French, German, Italian, Spanish, etc.).

${ }^{6}$ We consider English not only as the main language of our students, but also as a bridge between languages.

${ }^{7}$ In French Studies, the module Sounds of the Languages is integrated in the lab sessions.

8150 students across the various language programs participated in the pilot project.

\section{Bibliography}

Belshaw, D. A. J. (2012). What is 'digital literacy'? A Pragmatic investigation, [Doctoral theses, Durham University], E-Theses Online Services (EThOS). https://ethos.bl.uk/OrderDetails.do?uin=uk.bl.ethos.548838

Block, D. (2003). The Social Turn in Second Language Acquisition. Georgetown University Press.

Cunningham, U. (2015). Language teachers' need for linguistics. Te Reo, 58, 77-94. Available at https://www.diva-portal.org/smash/get/diva2:1236535/FULLTEXT01.pdf 
Barysevich, Alena, Liz Smeets and School of Languages and Literatures. « Fundamentals of Language and Language Learning: A Collaborative Initiative for the Implementation of a Common Online Language Training Component in the First-Year Language Curriculum. » Nouvelle Revue Synergies Canada, №14 (2021)

Cummins, J. (1981). Four Misconceptions about Language Proficiency in Bilingual Education. The Journal for the National Association for Bilingual Education, 5(3), 31-45.

DeKeyser, R. (2003). Implicit and explicit learning. In C. J. Doughty \& M. H. Long (Eds.) The Handbook of Second Language Acquisition. Oxford: Blackwell Publishing. doi: 10.1002/9780470756492

Dekeyser, R. \& Goretti, P. B. (2015). The Effectiveness of Processing Instruction in L2 Grammar Acquisition: A Narrative Review. Applied Linguistics, 36(3), 290-305. doi:10.1093/applin/amu071

Donato, C. \& Oliva, C.J. (2016). The Future is Multilingual: French, Italian, and Portuguese for Spanish Speakers. ADFL Bulletin, 44, 112-127.

Donato, C. \& Oliva, C.J. (2014). The Ties that Bind: Italian for Spanish Speakers in Intercomprehension. In R. Dolci (Ed.), Intercomprehension and multilingualism: Teaching Italian to Romance Languages Speakers (pp. 61-78). New York: Calandra Institute Transactions.

Ellis, N. C. (2005). At the Interface: Dynamic Interactions of Explicit and Implicit Language Knowledge. Studies in Second Language Acquisition, 27(2), 305-352.

Ellis, R. (2009). Implicit and Explicit Knowledge in Second Language Learning, Testing and Teaching. Buffalo and Bristol: Multilingual Matters.

Ellis, R. (2012). Language Teaching Research and Language Pedagogy. Oxford: Wiley-Blackwell.

Ellis, R. \& Shintani, N. (2014). Exploring Language Pedagogy Through Second Language Acquisition Research. Abingdon/New York: Routledge.

Escudé, P. et Janin, P. (2010). Le point sur l'intercompréhension, clé du plurilinguisme. Paris: CLE International.

Galante, A. (2021). Translation as a pedagogical tool in multilingual classes: Engaging the learner's plurilingual repertoire. Translation and Translanguaging in Multilingual Contexts Journal, 7(1), 106-123. doi: $\underline{10.1075 / \text { ttmc.00064.gal }}$

García, O. (2011). From Language Garden to Sustainable Languaging: Bilingual Education in a Global World. Perspectives: A publication of the National Association for Bilingual Education, Sept/Oct, 5-9.

ofeliagarciadotorg.files.wordpress.com/2011/02/2012nabenewsletter_34n1_nov2011_dec2011.pdf

Germain, C. (2010). Didactique générale, didactique des langues et linguistique appliquée. Canadian Journal of Applied Linguistics, 3(1-2), 23-33. Retrieved from

https://journals.lib.unb.ca/index.php/CJAL/article/view/19822

Godwin-Jones, R. (2011). Emerging Technologies. Autonomous Language Learning. Language Learning \& Technology, 15, 4-11.

Kramsch, C. (2009). The Multilingual Subject: What foreign language learners say about their experience and why it matters. Oxford, UK: Oxford University Press.

Marshall, S. \& Moore, D. (2013). 2B or Not 2B Plurilingual? Navigating Languages Literacies, and Plurilingual Competence in Postsecondary Education in Canada [Special issue]. Plurilinguism in TESOL, 47(3), $472-499$. 
Barysevich, Alena, Liz Smeets and School of Languages and Literatures. « Fundamentals of Language and Language Learning: A Collaborative Initiative for the Implementation of a Common Online Language Training Component in the First-Year Language Curriculum. » Nouvelle Revue Synergies Canada, №14 (2021)

McManus, K., \& Marsden, E. (2017). L1 Explicit Instruction Can Improve L2 Online and Offline Performance. Studies in Second Language Acquisition, 39, 459-492.

McManus, K., \& Marsden, E. (2019a). Signatures of automaticity during practice: Explicit instruction about L1 processing routines can improve L2 grammatical processing. Applied Psycholinguistics, 40, $205-234$.

McManus, K., \& Marsden, E. (2019b). Using Explicit Instruction About L1 to Reduce Crosslinguistic Effects in L2 Grammar Learning: Evidence from Oral Production in L2 French. Modern Language Journal, 103, 459-480.

Moore. D. (2006). Plurilinguismes et école. Editions Didier, collection LAL, Paris, 2006.

Moore D., Lau S.M.C., Van Viegen S. (2020) Mise en Écho des Perspectives on Plurilingual Competence and Pluralistic Pedagogies: A Conversation with Danièle Moore. In S. Lau, S. Van Viegen (Eds.), Plurilingual Pedagogies. Educational Linguistics, vol 42. Springer, Cham. https://doi.org/10.1007/978-3-030-36983-5 2

Oliva, C.,Donato, C.,Ricciardelli, F., (2019). Translation and Translanguaging Pedagogies in Intercomprehension and Multilingual Teaching. - Pédagogies de traduction et de translanguaging dans le contexte de l'intercompréhension et de l'enseignement plurilingue. Translanguaging: Opportunities and challenges in a global world, 10, 157-182. Cahiers de I'ILOB - OLBI Working Papers. https://digitalcommons.bryant.edu/cgi/viewcontent.cgi?article=1000\&context=lang jou

Piccardo, E. (2018). Plurilingualism: Vision, Conceptualization, and Practices. In P. Trifonas, \& T. Aravossitas (Eds.), Springer International Handbooks of Education. Handbook of Research and Practice in Heritage Language Education (pp. 207-226). New York, NY: Springer International Publishing. doi:10.1007/978-3-31938893-9_47-1

Piccardo, E. \& Galante A. (2017) Plurilingualism and Agency in Language Education. The Role of Dramatic Action-Oriented Tasks. In J. Choi \& S. Ollerhead (Eds.), Plurilingualism in Teaching and Learning: Complexities Across Contexts (pp. 147-164). New York: Routledge.

Piccardo. E., \& Puozzo, I. (Eds.). (2015). From second language pedagogy to the pedagogy of 'plurilingualism': a possible paradigm shift?/De la didactique des langues à la didactique du plurilinguisme: un changement de paradigme possible? The Canadian Modern Language Review/La Revue Canadienne des langues vivantes (CMLR/RCLV), 71(4).

Swain, M. (2018). Applied linguistics: A Consumer's View. Language Teaching, 51(2), $246-261$. doi:10.1017/S0261444818000058

Tokuhama-Espinosa, T. (2010). Mind, Brain, and Education Science: A Comprehensive Guide to the New BrainBased Teaching. W.W.Norton \& Company.

VanPatten, Bill. (2017). While We're on the Topic: BVP on Language, Acquisition, and Classroom Practice. American Council on the Teaching of Foreign Languages (ACTFL).

VanPatten, B., \& Benati, A. G. (2010). Key Terms in Second Language Acquisition. London, UK: Bloomsbury Publishing.

White, Lydia. (1991). Adverb placement in second language acquisition: Some effects of positive and negative evidence in the classroom. Second Language Research, 7, 133-161. Available at https://www.jstor.org/stable/43104427 
Barysevich, Alena, Liz Smeets and School of Languages and Literatures. " Fundamentals of Language and Language Learning: A Collaborative Initiative for the Implementation of a Common Online Language Training

Component in the First-Year Language Curriculum. » Nouvelle Revue Synergies Canada, №14 (2021)

Wiggins, G. et McTighe, J. (2011). The Understanding by Design Guide to Creating High Quality Units. Alexandria, Virginie: ASCD.

\section{APPENDIX A}

Appendix 1: Structure of each module

\section{Figure 1}

\section{Map of languages}

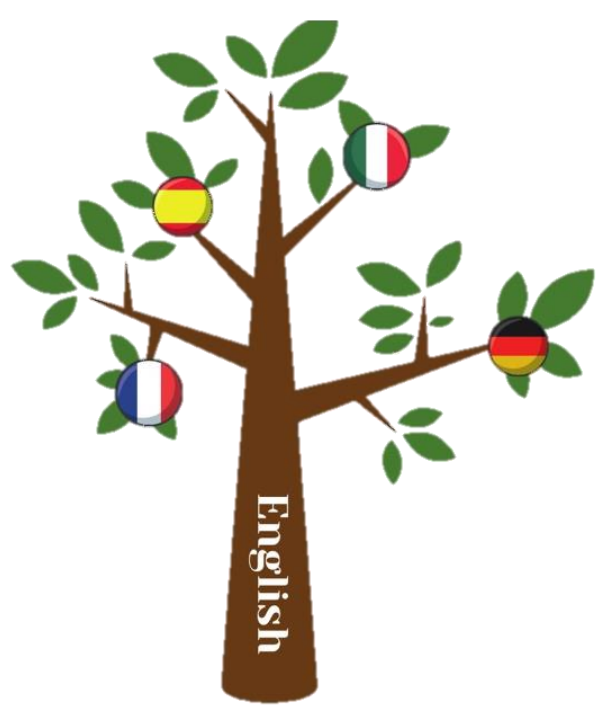


Barysevich, Alena, Liz Smeets and School of Languages and Literatures. «Fundamentals of Language and Language Learning: A Collaborative Initiative for the Implementation of a Common Online Language Training

Component in the First-Year Language Curriculum. » Nouvelle Revue Synergies Canada, №14 (2021)

\section{Figure 2}

\section{BOPPPS model for lesson planning}

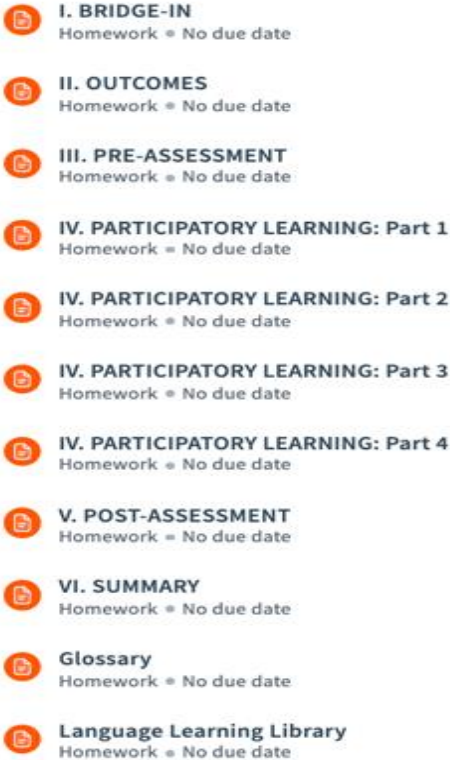

Figure 3

Inside of each module (French as a second language)
I. BRIDGE-IN
(E) BRIDGE-IN $\mid F R$
- II. OUTCOMES
† III. PRE-ASSESSMENT
I) PRE-ASSESSMENT |FR
IIV. PARTICIPATORY LEARNING: Part 1
g) PL - PART 1 $\mid F R$
IIV. PARTICIPATORY LEARNING: Part 2
E) PL-Part 2-FR|Plurals
IIV. PARTICIPATORY LEARNING: Part 3
E) PL-Part 3-FR/Phonetics
E) PL- Part 3 - FR |Morphology
E) PL-Part 3-FR | Syntax
IIV. PARTICIPATORY LEARNING: Part 4
I) PL-Part $4 \mid F R$
E V. POST-ASSESSMENT
ㄱ. POST-ASSESSMENT /FR
E VI. SUMMARY
G Glossary
(E) Language Learning Library
E. Post-Module Questionnaire 
Barysevich, Alena, Liz Smeets and School of Languages and Literatures. « Fundamentals of Language and Language Learning: A Collaborative Initiative for the Implementation of a Common Online Language Training

Component in the First-Year Language Curriculum. » Nouvelle Revue Synergies Canada, №14 (2021)

Appendix 2: Feedback from SOLAL faculties and students

\section{Table 1}

\section{Students' feedback on the Fundamentals of Language and Language Learning module}

- $\quad$ This Module is very important as I feel like many native English speakers are not actually educated on how our language is structured. This makes learning other languages difficult.

- $\quad$ The interactive activities made the learning engaging.

- $\quad$ The module was effective because it works through concepts step by step and in English at first to help you grasp what you are learning.

- It was a helpful learning experience that helped my foundation of language in English and Spanish.

- It was interesting, simple, and accessible.

- It $\quad$ It raised my awareness about languages I speak and learn.

- $\quad$ The Module was really informative and presented basic properties of Italian through the lens of linguistics, something I have never learned before.

- $\quad$ This module was unlike my other French courses, it guided me in strategic ways to learn languages.

- I think it's important to know the basic structures of languages in order to learn others.

- I think it does a great job at talking about how languages can be similar and different and why it is important to focus on the basics in your own language before learning a new one.

- $\quad$ I thought it was useful even to better understand your first language.

- I would recommend this Module because formation of words and sentence structure are an important piece of understanding a new language.

- $\quad$ I would recommend this module to my peers because it gave me a greater appreciation for basic sentence structure. The knowledge I gained will not only supplement my learning of the Italian language but also my success in the English language.

\section{Table 2}

Feedback from SOLAL faculty members

\section{Margot Irvine (Associate Professor, European Studies, French Studies, Director of the School of Languages and Literatures):}

The Fundamentals of Language and Language Learning, developed by a team of researchers and instructors, are particularly well-suited to a multilingual School like the School of Languages and Literatures at the University of Guelph. The project has drawn on the expertise of language teachers in multiple languages and on researchers with backgrounds in applied linguistics. In addition to serving our students well, as Director of the School, I welcome it as a federating project that recognizes the similarities shared by second language learners, despite the language they are studying, as well as the similar challenges that second language instructors face, independent of the language that they teach. I expect that the language instructors who implement it will continue to collaborate with each other to arrive at best practices in language pedagogy and hope to see the modules extended to all of the languages taught in the School. From an administrative perspective within SOLAL, I recognize this as an innovative, unifying project that allows instructors and researchers to collaborate, while providing an optimal learning opportunity for our students. 
Barysevich, Alena, Liz Smeets and School of Languages and Literatures. « Fundamentals of Language and Language Learning: A Collaborative Initiative for the Implementation of a Common Online Language Training Component in the First-Year Language Curriculum. » Nouvelle Revue Synergies Canada, №14 (2021)

Sandra Parmegiani (Associate Professor, European Studies, Italian Studies):

The Fundamentals of Language and Language Learning has been a wonderful addition to the strategies of language learning in the School of Languages and Literatures at the University of Guelph. In Winter 2021 three of the modules were introduced in first-year Italian classes and it was extremely rewarding to observe how the goals of intercomprehension and plurilingual competence in language learning enhanced both instructors' and students' awareness of language interconnectedness and fostered the acquisition of learning strategies. Students demonstrated a solid engagement with the content of the modules and in their self-reflections provided an extensive array of comments on almost every aspect of the material they worked through. This great variety of responses provided the best insight and validation that the invitation to explore the interconnectedness of languages and to reflect on their main structures, properties and concepts, is perceived as a most useful and enriching experience, both linguistically and culturally. Students demonstrated also an appreciation for their own struggles with pronunciation and in some cases expressed a new understanding of the difficulties encountered by English learner in L2 pronunciation. In the multicultural and linguistically diverse society these students inhabit, such awareness translates in cultural enrichment and critical thinking.

The team of researchers and instructors from SOLAL have built a tool that opens a new frontier in language learning, and they have done it in a rigorous and effective way. The design is superb, the implementation of the BOPPPS model facilitates the students' progression through the modules, provides a set of dynamic information, incremental challenges and metalinguistic reflections that help them navigate the material with a high degree of gratification. The Fundamentals of Language and Language Learning are also of great help to instructors because they provide students with a strong experience in autonomous language learning. They ultimately enhance the classroom experience thanks to an increase of students' pre-existing knowledge and their appetite for a comparative and inquisitive approach to languages.

\section{Rosario Gomez (Associate Professor, Linguistics, Spanish \& Hispanic Studies)}

The Fundamentals of Language and Language Learning modules offer an impressive breadth of topics about how language is organized at the various subdisciplines like word structure, sentence structure, and the sound system and the rules that govern it. These modules are not only useful to students of the languages taught at the School of Languages and Literatures, but they offer a great introduction to students of Linguistics. We cannot teach or learn a language without delving into the world of Linguistics and in the Fundamentals of Language and Language Learning, the team of researchers and language instructors introduce linguistic concepts in a very accessible, contextual, non-technical way. I find the interactive activities very effective, fun, and informative.

Students are encouraged to compare and contrast the processes behind the workings of language. As most of us know, second language learning is different from first language learning. The former benefits from explicit instruction which is made a lot easier when students draw information that they already possess through mastery of their first language. The modules help students make this connection. Once students have completed these modules, they will have a general understanding of how languages work and will come into a Spanish, French, Italian, German, or a Linguistics class well equipped to take full advantage of the material presented.

\section{Denise Mohan (Associate Professor, Spanish \& Hispanic Studies)}

The Fundamentals of Language and Language Learning modules provide a variety of benefits to students of Spanish as a second language. During the winter 2021 semester, students of Spanish who completed the modules were quick to express their appreciation for them, reporting that they introduced valuable concepts that contributed positively to their learning journey. As an instructor, I am impressed by the well-developed content of the modules which provide students with foundational knowledge about the structure of language in general and invite them to compare and contrast the structures of languages they already know with Spanish, the one they are beginning to learn. In this way, students can see the patterns that exist among different languages and examine 
Barysevich, Alena, Liz Smeets and School of Languages and Literatures. « Fundamentals of Language and Language Learning: A Collaborative Initiative for the Implementation of a Common Online Language Training Component in the First-Year Language Curriculum. » Nouvelle Revue Synergies Canada, №14 (2021)

how languages differ in structure and use. In the Canadian context, a large number of students studying Spanish have already studied French and often rely on French pronunciation, vocabulary and grammar to navigate their way through Spanish. Native speakers of English do the same. Through their engagement with the content of the four modules students become aware of the similarities and differences between their experienced languages and can begin to navigate between them in the classroom, equipped with the knowledge gleaned from the modules. Through an impressive array of interactive input from multiple current content sources, Dr. Barysevich and team introduce many concepts that are often, due to time constraints, not addressed in the beginner level Spanish classroom and indeed, in many foreign/second language classrooms. In a non-threatening way, students are urged to explore their assumptions about language, are introduced to new information in manageable increments, and through a scaffolded approach to evaluation, they complete low-stakes assessment activities. This approach integrates well with the flipped classroom model as students, having previously completed any section of a module, enter the classroom with both theoretical and practical knowledge. This allows the instructor to focus on higher order in-class activities which engage students and challenge them to evaluate what they learn in the modules as they apply it in the classroom to create new learning in Spanish for the world beyond the classroom.

\section{Dawn M. Cornelio (Associate Professor, French Studies)}

The team who developed The Fundamentals of Language Learning have contributed an incredibly useful tool to language learning. The graduated modules are created in such a way as to make this learning intuitive and self-explanatory; they highlight to students their current understanding of how languages work, and they provide them with the tools to expand and apply this knowledge. Beginning with the basics of the parts of speech sets students up for success when they will encounter lessons built around these parts of speech throughout their studies. In addition to laying this groundwork, the modules free up valuable class time that previously had to be used to (too quickly and superficially) present these concepts; the time saved can then be dedicated to more interactive and communicative in-class activities. With the online format, students can work at their own pace to master the topics which is not often the case in synchronous learning situations. And, beyond these benefits for both students and instructors, I can honestly say that I, after more than 30 years of teaching, happily learned a number of things in going through the modules myself. What else can you ask for?

\section{Enrica Aurora Cominetti (Lecturer, Italian Studies):}

While teaching the Introductory Italian I during the Winter 21 semester I was able to experience firsthand the extent to which my students benefited from completing the Language Modules' self-study material. In learning and practicing with the modules' interactive content, the students acquired a more thorough knowledge of the structure and functioning of Italian as well as of the English language. They were positively impacted by the implementation of these learning resources as most of them reported feeling more confident about and aware of their language learning journey after completing the modules. The effectiveness of this program on the fundamentals of language resides not only in its theoretical explanations which are tailored to students' needs, but also and foremost in its wide array of interactive activities and audiovisual materials. I found this variety of study resources to be incredibly stimulating and helpful for students as it would provide them with a teaching method that, in its being systematic yet diversified, multisensory and multimedia, is deemed to appeal to different learning styles.

\section{Wes Lindinger (Lecturer, German Studies):}

The Fundamentals of Language and Language Learning mini-course takes on the important task of teaching students in first-year language courses basic linguistic concepts that they are often lacking upon the beginning of their university studies. The cross-linguistic, comparative approach taken in the teamdeveloped modules, and represented in a well-structured and pedagogically-sound way, show the potential to be highly effective with learners of German due to the typological relationship between German and English. While both English and German have, for example, many Latinate loanwords, 
Barysevich, Alena, Liz Smeets and School of Languages and Literatures. « Fundamentals of Language and Language Learning: A Collaborative Initiative for the Implementation of a Common Online Language Training

Component in the First-Year Language Curriculum. » Nouvelle Revue Synergies Canada, №14 (2021)

they also share a large inventory of lexical items from common, Germanic etymological roots which are sometimes not apparent to new learners. Through the modules, however, an understanding of sound changes within the Germanic languages can help students to identify cognates that may not have been initially obvious. A comparative approach to the grammatical structures of the languages focusing on the similarities is likewise useful. Learners of German are sometimes intimidated by the written length of German compound words but realizing that English effectively compounds nouns the same way while simply writing them broken up gives students an early ability to begin breaking down German compounds, making both comprehension and pronunciation easier. The formation of plurals in German is also sometimes complicated for students but seeing that English also does not always simply use an -s suffix can help them draw parallels between the languages, particularly with cognates where they can trust their "Germanic gut", such as goose/geese (Gans/Gänse) or foot/feet (Fuß/Füße). The comparative approach helps as well to demystify concepts like German's case system. By seeing the way case markings are used to convey the role of a word in a sentence, compared to how English achieves this through methods like prepositions and word order, students can relate this new concept back to their knowledge of English. This, in turn, strengthens their understanding of English and how it functions. This deepened understanding of how languages work in general serves to make language-learners better communicators, regardless of field or course of studies.

Pilar Rodriguez Mata (Lecturer, Spanish \& Hispanic Studies):

As someone who teaches Spanish as a second language, the lack of knowledge about basic linguistic terms is always an obstacle in the classroom. Time is lost on basic concepts and students get left behind easily. These modules allow students to start a class already knowing the base of what they will be learning. There's no need to spend half the class explaining what the subject and the direct and indirect objects are; we can go straight to how to use indirect and direct object pronouns correctly. We can show them how pronunciation works, thanks to the knowledge of phonetics that they did not have before. They can create and recognise words by understanding positive transfer and morphology. These modules helped my students feel more secure in their knowledge and allow me to focus my effort on the more complicated content, because the basics were already covered. 